\title{
ANALISIS MERKURI (Hg) PADA LOTION PEMUTIH YANG BEREDAR DI PASAR RAYA KOTA PADANG MENGGUNAKAN SPEKTROFOTOMETER SERAPAN ATOM
}

\author{
Afdhil Arel $^{1 *}$, Regina Andayani' ${ }^{2)}$, Aulia Rahmi ${ }^{3)}$, Wida Ningsih ${ }^{1)}$ \\ ${ }^{1)}$ Program Studi Farmasi Fakultas Sains dan Teknologi Universitas Muhammadiyah Sumatera \\ Barat \\ ${ }^{2)}$ Fakultas Farmasi Universitas Andalas \\ ${ }^{3)}$ Sekolah Tinggi Farmasi Indonesia Perintis \\ "E-mail : afdhilarel@umsb.ac.id
}

\begin{abstract}
INTISARI
Lotion pemutih merupakan campuran bahan dengan khasiat bisa memutihkan kulit atau memucatkan noda hitam (coklat) pada kulit. Penambahan merkuri dalam lotion pemutih dapat menimbulkan berbagai hal, mulai dari perubahan warna kulit yang pada akhirnya dapat menyebabkan bintik-bintik hitam pada kulit, alergi dan iritasi kulit. Pemakaian merkuri dengan dosis tinggi dapat menyebabkan kerusakan otak permanen serta dapat menyebabkan kanker. Telah dilakukan penelitian analisis kandungan merkuri dalam lotion pemutih merk A, B dan C yang beredar di Pasar Raya Kota Padang. Ekstraksi merkuri dalam lotion pemutih dilakukan dengan cara destruksi basah dengan larutan $\mathrm{HNO}_{3}$ pekat dan $\mathrm{H}_{2} \mathrm{SO}_{4}$ pekat selama 2 jam pada suhu $\pm 95^{\circ} \mathrm{C}$ sampai diperoleh larutan bening. Merkuri yang terlarut dalam larutan bening ini diukur serapannya dengan alat Spektrofotometer Serapan Atom menggunakan lampu katoda berongga merkuri pada panjang gelombang $253,7 \mathrm{~nm}$. Hasil dari penelitian ini adalah sampel merek A, B dan C terdeteksi mengandung logam merkuri dengan kadar berturut-turut adalah $0,3347 \mu \mathrm{g} / \mathrm{g} ; 0,7917 \mu \mathrm{g} / \mathrm{g}$ dan $0,7981 \mu \mathrm{g} / \mathrm{g}$. Lotion pemutih yang beredar di Pasar Raya tersebut tidak memenuhi Peraturan Kepala BPOM RI No.18 Tahun 2015 yang isinya melarang penggunaan merkuri dalam sediaan kosmetika.
\end{abstract}

Kata kunci: merkuri, lotion pemutih, Spektrofotometer Serapan Atom

\begin{abstract}
Whitening lotion is a mixture of chemicals or other ingredients with properties that can whiten the skin or blemish black (brown) on the skin. The use of mercury in whitening lotions can cause a variety of things, ranging from skin discoloration which can ultimately cause black spots on the skin, allergies and skin irritation. The using of mercury in high dose can cause permanent brain damageand cancer. An analysis of mercury content in the whitening lotion brands $A, B$ and $C$ circulating at market in Padang city has been conducted. Extraction of mercury in the whitening lotion was done by wet destruction with a concentrated $\mathrm{HNO}_{3}$ solution and concentrated $\mathrm{H}_{2} \mathrm{SO}_{4}$ for 2 hours at a temperature of $\pm 95^{\circ} \mathrm{C}$ until a clear solution is obtained. The clear solution was measured by absorption with an Atomic Absorption Spectrophotometer using a mercury hollow cathode lamp at a wavelength of $253.7 \mathrm{~nm}$. The results of this study were samples of brands $A, B$ and $C$ detected containing mercury metals with successive levels of $0.3347 \mu \mathrm{g} / \mathrm{g} ; 0,7917 \mu \mathrm{g} / \mathrm{g}$ and $0,7981 \mu \mathrm{g} / \mathrm{g}$. The whitening lotions that circulate in market do not meet the Head of BPOM RI Regulation No.18 of 2015 whose contents prohibit the use of mercury in cosmetics preparations.
\end{abstract}

Keywords: mercury, whitening lotion, Atomic Absorption Spectrophotometer 
"Corresponding author:

Afdhil Arel

Prodi Farmasi Fakultas Sains dan TeknologiUniversitas Muhammadiyah Sumatera Barat

Jalan Pasir Kandang No. 4 Koto Tangah Padang

E-mail : $\underline{\text { afdhilarel@umsb.ac.id }}$

\section{PENDAHULUAN}

Penampilan cantik dan menarik bagi para wanita identik dengan kulit yang putih bersih tanpa noda. Kebanyakan kaum wanita berusaha berpenampilan menarik sehingga senantiasa menjaga dan memperbaiki kesehatan kulitnya agar tampak putih dan cerah. Seiring berkembangnya teknologi perawatan kulit dan klinik-klinik kecantikan yang tersebar di Indonesia, perawatan kulit telah menjadi tujuan tersendiri bagi kaum wanita modern dan merupakan sebuah kebutuhan bagi seorang wanita (Tranggono dan Latifah, 2007). Salah satu sediaan kosmetika yang banyak digunakan oleh masyarakat terutama kaum wanita untuk memutihkan kulit yaitu hand and body lotion whitening.

Produsen yang tidak bertanggung jawab seringkali menambahkan logam merkuri $(\mathrm{Hg})$ sebagai pemutih kulit dalam sediaan kosmetika. Logam merkuri ini merupakan bahan yang berbahaya karena dalam jangka panjang dapat menimbulkan kerusakan pada organ tubuh dan juga bersifat toksik (Palar, 2008). Merkuri adalah unsur yang mempunyai nomor atom 80 dengan berat molekul relatif 200,59. Merkuri diberikan simbol kimia $\mathrm{Hg}$ yang berasal dari bahasa Yunani hydrargyricum yang berarti cairan berwarna perak (Darmono, 2001). Menurut Peraturan Menteri Kesehatan RI No.445/MENKES/PER/V/1998 menyatakan bahwa dalam kadar yang sedikitpun merkuri dapat bersifat racun. Merkuri dapat menimbulkan perubahan warna kulit, bintik-bintik hitam, alergi, iritasi, serta pada pemakaian dosis tinggi dapat menyebabkan kerusakan permanen otak, ginjal dan gangguan perkembangan janin. Bahkan paparan jangka pendek merkuri dalam dosis tinggi dapat menyebabkan muntah-muntah, diare dan kerusakan paru-paru serta merupakan zat karsinogenik (BPOM RI, 2011).

Penggunaan lotion dengan komposisi zat berbahaya yang terkandung di dalamnya perlu diperhatikan karena penggunaan jangka panjang dan berlebihan dapat membahayakan kesehatan. Penelitian yang dilakukan Fithriani dkk.(2013) terhadap 3 sampel kosmetika herbal berupa krim pemutih, telah ditemukan adanya kandungan merkuri berturut-turut sebesar $0,56 \% ; 0,28 \%$; dan 0,45\%. Kadar Hg pada sampel tersebut melanggar Peraturan Kepala BPOM RI NO.18 tahun 2015 yang isinya melarang penggunaan merkuri dalam sediaan kosmetika. Metode Spekrofotometer Serapan Atom (SSA) merupakan metode analisis senyawa yang spesifik untuk setiap unsur, memiliki sensitifitas yang tinggi serta penggunaan sampel yang relative sedikit (Khopkar, 1990). Penelitian ini bertujuan untuk mengetahui ada atau tidaknya kandungan logam merkuri dalam lotion pemutih yang beredar di Pasar Raya Kota Padang menggunakan Spekrofotometer Serapan Atom (SSA).

\section{METODE PENELITIAN}

\section{Bahan dan alat}

Bahan yang digunakan adalah lotion pemutih yang terdiri dari 3 merek $\mathrm{A}, \mathrm{B}$ dan $\mathrm{C}$ diperoleh dari Pasar Raya Kota Padang, asam nitrat pekat p.a (Merck), kalium iodida p.a (Merck), natrium hidroksida p.a (Merck), asam sulfat pekat p.a. (Merck), kalium permanganat 5\% p.a (Merck), kalium persulfate $5 \%$, hidroksilamin-NaCl $10 \%$ p.a (Merck), Timah (II) klorida 10\% p.a (Merck), aquadest, merkuri standar solution $\mathrm{Hg}\left(\mathrm{NO}_{3}\right)_{2} 1000 \mathrm{mg} / \mathrm{L}$ (Merck). Alat yang digunakan adalah Spektrofotometer Serapan Atom merek GBC tipe AA-932, Spektrofotometer Serapan Atom-uap dingin Hidrit Generation Tipe 3000 merek GBC (GBC HG 3000), lampu katoda berongga Hg, pipet mikro, penangas listrik, timbangan digital, labu destruksi dan alat-alat gelas lainnya.

\section{Penyiapan sampel dengan cara destruksi basah}

Sampel ditimbang sebanyak 1,0 gram, dimasukkan ke dalam labu destruksi, ditambahkan 5 $\mathrm{mL} \mathrm{H}_{2} \mathrm{SO}_{4}$ pekat, 2,5 $\mathrm{mL} \mathrm{HNO}_{3}$ pekat dan larutan $\mathrm{KMnO}_{4} 5 \%$ sebanyak $15 \mathrm{~mL}$, ditunggu sampai 15 menit (bila warna ungu hilang ditambahkan lagi $\mathrm{KMnO}_{4}$ sampai warna ungu tidak hilang). Kemudian ditambahkan $8 \mathrm{~mL} \mathrm{~K}_{2} \mathrm{~S}_{2} \mathrm{O}_{8} 5 \%$, dipanaskan dalam penangas air selama 2 jam pada suhu 
$95^{\circ} \mathrm{C}$. Setelah itu sampel didinginkan pada suhu kamar dan ditambahkan secukupnya larutan hidroksilamin- $\mathrm{NaCl} 10 \%$ untuk mereduksi kelebihan $\mathrm{KMnO}_{4}$, kemudian ke dalam larutan ditambahkan $5 \mathrm{ml} \mathrm{SnCl} \mathrm{Sn}_{2} 10 \%$ (Eaton, 2005; Erasiska dan Hanifah, 2015).

\section{Analisis kualitatif $\mathbf{H g}$ dalam sampel}

1) Pereaksi Kalium Iodida (KI)

Larutan sampel sebanyak $2 \mathrm{ml}$ dimasukkan ke dalam tabung reaksi lalu ditambahkan perlahan-lahan larutan KI. Hasil yang positif ditunjukkan dengan terbentuknya endapan merah orange. Penambahan pereaksi berlebihan akan melarutkan endapan.

$$
\mathrm{Hg}^{2+}+2 \mathrm{I}^{-} \rightarrow \mathrm{HgI}_{2} \downarrow
$$

2) Pereaksi Natrium Hidroksida $(\mathrm{NaOH})$

Larutan sampel sebanyak $2 \mathrm{ml}$ dimasukkan ke dalam tabung reaksi lalu ditambahkan perlahan-lahan larutan $\mathrm{NaOH}$. Hasil positif ditunjukkan dengan terbentuknya endapan berwarna kuning.

$$
\mathrm{Hg}^{2+}+2 \mathrm{OH}^{-} \rightarrow \mathrm{Hg}(\mathrm{OH})_{2} \downarrow
$$

\section{Penentuan kadar logam merkuri (Hg) dengan SSA}

Larutan hasil destruksi dimasukkan ke dalam labu destruksi $50 \mathrm{~mL}$ dan ditambahkan dengan aquadest sampai tanda batas. Setelah itu diukur serapannya dengan Spektrofotometer Serapan Atom pada panjang gelombang 253,7 $\mathrm{nm}$. Hasil pengujian dianalisis menggunakan Anava satu jalan dengan taraf kepercayaan $95 \%$.

\section{HASIL DAN PEMBAHASAN}

Dalam penelitian ini digunakan 3 sampel berupa lotion pemutih merek A, B dan C yang diperoleh dari Pasar Raya Kota Padang. Pengambilan sampel berdasarkan kecenderungan pemakaian konsumen yang tinggi terhadap produk tersebut. Sebelum sampel diuji secara kualitatif dan kuantitatif terlebih dahulu dilakukan pengolahan sampel dengan cara destruksi basah. Sampel didestruksi basah karena logam merkuri mempunyai titik didih yang rendah dan merupakan logam yang paling mudah menguap di antara logam lainnya (Palar, 2008). Destruksi basah menggunakan asam kuat dan oksidator yaitu $\mathrm{H}_{2} \mathrm{SO}_{4}$ pekat, $\mathrm{HNO}_{3}$ pekat, $\mathrm{KMnO}_{4} 5 \%$ dan $\mathrm{K}_{2} \mathrm{~S}_{2} \mathrm{O}_{8} 5 \%$. Campuran kedua larutan di atas lebih dikenal sebagai asam kuat dan oksidator. Tujuan penambahan asam kuat dan oksidator yaitu untuk memutuskan ikatan $\mathrm{Hg}$ organik menjadi $\mathrm{Hg}$ anorganik. Kemudian ditambahkan pereduksi kuat yaitu Hidroksilamin- $\mathrm{NaCl}$ dan $\mathrm{SnCl}_{2}$. Hidroksilamin- $\mathrm{NaCl}$ berfungsi untuk mereduksi kelebihan $\mathrm{KMnO}_{4}$. Bahan $\mathrm{SnCl}_{2}$ sebagai reduktor untuk proses atomisasi atau proses pembentukan atom-atom bebas merkuri, sehingga terjadi reaksi sebagai berikut:

$2 \mathrm{Hg}^{2+}+\mathrm{Sn}^{2+} \longrightarrow 2 \mathrm{Hg}^{+}+\mathrm{Sn}^{4+}$
$2 \mathrm{Hg}^{+}+\mathrm{Sn}^{2+} \longrightarrow 2 \mathrm{Hg}^{0}+\mathrm{Sn}^{4+}$

Analisis kualitatif dilakukan dengan reaksi pengendapan atau reaksi warna (Vogel, 1985), sedangkan analisis kuantitatif menggunakan Spektrofotometri Serapan Atom. Penggunaan instrumen ini dipilih karena lebih spesifik dan selektif dalam pengukuran logam-logam berat dengan konsentrasi kecil, dan waktu yang diperlukan singkat (Day dan Underwood, 2002). Absorban logam merkuri dideteksi pada panjang gelombang 253,7 nm. Hasil analisis kualitatif yang telah dilakukan pada semua sampel lotion pemutih merek $\mathrm{A}$ dan $\mathrm{C}$ menunjukkan hasil negatif (-) dengan menggunakan pereaksi $\mathrm{KI}, \mathrm{NaOH}$, sedangkan sampel $\mathrm{B}$ menunjukkan hasil positif (+) dengan menggunakan pereaksi $\mathrm{NaOH}$ (Tabel I).

Tabel I. Pemeriksaan kualitatif merkuri dalamlotion pemutih

\begin{tabular}{ccc}
\hline $\begin{array}{c}\text { Sampel } \\
\text { (Lotion Pemutih) }\end{array}$ & KI & Pereaksi \\
A & Negatif & NaOH \\
B & Negatif & Positif \\
C & Negatif & Negatif \\
\hline
\end{tabular}

Pemeriksaan kuantitatif kandungan logam merkuri pada lotion pemutih merek A, B, dan C dilakukan dengan metoda Spektrofotometri Serapan Atom karena dapat menentukan kadar logam 
dengan kepekaan yang tinggi yaitu kurang dari 1 ppm. Jenis Spektrofotometri Serapan Atom yang digunakan pada penelitian ini untuk mendapatkan kadar merkuri adalah Spektrofotometri Serapan Atom Uap-Dingin. Teknik uap dingin ini terbatas hanya untuk penentuan merkuri dan tidak dapat digunakan untuk elemen lain, karena tidak ada elemen lain yang dapat direduksi secara kimiawi untuk menghasilkan atom-atom bebas pada temperatur kamar (Beauty dkk., 1993).

Parameter validasi suatu metode analisis seperti linearitas, batas deteksi dan batas kuantifikasi perlu dilakukan untuk verifikasi bahwa metode tersebut dapat digunakan untuk analisis suatu analit sasaran. Linearitas merupakan kemampuan suatu metode untuk memperoleh hasil-hasil uji secara langsung proporsional dengan konsentrasi analit pada kisaran yang diberikan.Tujuan lineritas ini dilakukan untuk melihat seberapa baik kurva kalibrasi yang menghubungkan antara respon (y) dengan konsentrasi (x) (Harmita, 2004). Hasil pengukuran larutan seri standar merkuri didapatkan kurva kalibrasi dengan persamaan regresi linear $\mathrm{y}=-0,002648+0,002131 \mathrm{x}$ dan nilai koefisien korelasi (r) adalah 0,9997. Hal ini menunjukkan bahwa hubungan linier yang didapatkan ideal karena nilai koefisien korelasi yang mendekati 1. Persamaan regresi linier tersebut digunakan dalam perhitungan kadar merkuri pada semua sampel.

Batas deteksi (LOD) merupakan kadar senyawa terkecil yang dapat dianalisis yang dapat memberikan respon signifikan, sedangkan batas kuantifikasi (LOQ) adalah jumlah senyawa terkecil yang dapat dianalisis (Buick dkk., 1990). Batas deteksi dan batas kuantifikasi dapat dihitung secara statistik melalui garis regresi linier dari kurva kalibrasi. Hasil yang didapat batas deteksi merkuri adalah $0,00182 \mu \mathrm{g} / \mathrm{mL}$, dan batas kuantifikasi $=0,00607 \mu \mathrm{g} / \mathrm{mL}$. Kegunaan dari batas deteksi dan batas kuantifikasi ini adalah untuk menunjukkan kepekaan metoda analisis yang baik untuk menentukan konsentrasi larutan sampel yang dianalisis.

Berdasarkan perhitungan kadar merkuri didapatkan kadar rata-rata dari sampel lotion pemutih dengan merek A sebanyak $0,3347 \mu \mathrm{g} / \mathrm{g}$, pada sampel lotion pemutih merek B yaitu sebanyak $0,7981 \mu \mathrm{g} / \mathrm{g}$, dan pada sampel lotion pemutih merek C yaitu sebanyak $0,7917 \mu \mathrm{g} / \mathrm{g}$ (Tabel II). Semua sampel tersebut positif mengandung merkuri sehingga tidak aman digunakan pada kulit dan telah melanggar Peraturan Kepala BPOM RI No.18 Tahun 2015 yang isinya melarang penggunaan merkuri dalam sediaan kosmetika.

Tabel II. Pemeriksaan kuantitatif kadar merkuri dalam lotion pemutih

\begin{tabular}{cc}
\hline $\begin{array}{c}\text { Sampel } \\
\text { (Lotion Pemutih) }\end{array}$ & Kadar Merkuri $(\boldsymbol{\mu g} / \mathbf{g})$ \\
\hline A & $0,3347 \pm 0,00001$ \\
B & $0,7981 \pm 0,00010$ \\
C & $0,7917 \pm 0,00014$ \\
\hline
\end{tabular}

Berdasarkan uji statistik menggunakan Anova satu jalan menunjukkan bahwa nilai $p<0,05$, artinya terdapat perbedaan signifikan pada data kandungan merkuri dalam sampel. Kemudian dilanjutkan dengan Uji Duncan menunjukkan bahwa lotion pemutih merek A terdapat perbedaan signifikan dengan lotion pemutih merek $\mathrm{B}$ dan lotion pemutih merek $\mathrm{C}$, namun tidak terdapat perbedaan signifikan antara lotion pemutih merek B dan lotion pemutih merek C. Dilihat dari hasil yang didapat bahwa kandungan merkuri antara merek $\mathrm{B}$ dan merek $\mathrm{C}$ memiliki kadar merkuri yang hampir sama dan lebih banyak dibandingkan dengan merek A. Namun demikian bukan berarti merek A lebih aman karena merkuri sama sekali tidak boleh terkandung dalam sediaan kosmetika sesuai Peraturan BPOM, 2015. Hasil analisis kuantitatif kandungan merkuri dalam 3 sampel produk kosmetik yang beredar menunjukkan bahwa 3 produsen yang berbeda sama-sama telah menambahkan merkuri ke dalam produk lotion pemutih. Ketiganya telah melanggar ketentuan BPOM dan seharusnya mendapatkan teguran ataupun sanksi. Namun perlu dipastikan juga apakah ketiganya benar-benar mendaftarkan produknya ke BPOM dan mempunyai ijin produksi kosmetika tersebut atau ternyata memang tidak mempunyai ijin tersebut. Pemutih kulit dapat membuat melanin berkurang, sehingga mengakibatkan kulit menjadi sensitif dengan cahaya matahari. Apabila digunakan dalam jangka waktu panjang, dapat menyebabkan penuaan dini dan kanker kulit. Berkurangnya kadar melanin, dampak sinar ultraviolet terhadap kulit menjadi meningkat.

Analisis Merkuri (Hg) pada Lotion Pemutih Yang Beredar di Pasar Raya Kota Padang... (Afdhil Arel) 
Paparan sinar ultraviolet secara berlebihan akan mempercepat terjadinya keriput serta memicu terjadinya kanker kulit (Tranggono dan Latifah, 2007).

\section{KESIMPULAN}

Lotion pemutih yang beredar di Pasar Raya Kota Padang ternyata positif mengandung merkuri.Lotion pemutih tersebut tidak memenuhi Peraturan Kepala BPOM RI No.18 Tahun 2015 yang isinya melarang penggunaan merkuri dalam sediaan kosmetika.

\section{UCAPAN TERIMA KASIH}

Ucapan terima kasih ditujukan kepada Kementerian Riset Teknologi dan Pendidikan Tinggi atas bantuan dana hibah skema Penelitian Produk Terapan tahun 2016.

\section{DAFTAR PUSTAKA}

Badan POM RI,2011,Melarang Produk Kosmetik Mengandung Bahan yang Berbahaya. Departemen Kesehatan Republik Indonesia, Jakarta.

Beauty, R., Kerber, D.Jack, D., 1993,Concepts, Instrumenstation and Techniques in Atomic Absorbtion Spechtrometry, Perkin Elmer Co, USA, 1,1 - 2,3.

Buick, A.R., Doing, M.V., Jeal, S.C., Land, G., McDowall, R.D., 1990,Method Validation in the Bioanallytical Laboratory, Journal of Pharmaceutical and Biomedical Analysis, 8(3): 625639.

Day, R.A., Underwood A.L., 2002, Analisa Kimia Kuantitatif,dierjemahkanoleh LisSopyan, Edisi IV,Erlangga,Jakarta.

Darmono, 2001, Lingkungan Hidup dan Pencemarannya, Hubungannya dengan Toksikologi Senyawa Logam, UI Press, Jakarta.

Eaton, D.A., 2005,Standard Methods for The Examination of Wather and Wastewather:Edition 21.

Erasiska, B.S., Hanifah, T.A., 2015, Analisis Kandungan Logam Timbal, Kadmium dan Merkuri dalam Produk Krim Pemutih Wajah, JOM FMIPA, 2(1): 1 - 7.

Fithriani, A., Zulharmita, Dinda,R.F.,2013,Identifikasi dan Penetapan Kadar Merkuri (Hg) dalam Krim Pemutih Kosmetik Herbal Menggunakan Spektrofotometri Serapan Atom, Jurnal Sains dan Teknologi Farmasi, 18(1).

Harmita, 2004, Petunjuk Pelaksanaan Validasi Metode dan Cara Perhitungannya. Review Artikel,Majalah Ilmu Kefarmasian,1(3): 117-135.

Khopkar, S.M., 1990,Konsep Dasar Kimia Analitik, diterjemahkan oleh Saptohardjo, UI-Press, Jakarta:274-275.

Palar, H., 2008, Pencemaran dan Toksikologi Logam Berat, Rineka Cipta, Jakarta.

Tranggono, R.I., Latifah, F., 2007, Buku Pegangan Ilmu Pengetahuan Kosmetik. PT. Gramedia Pustaka Utama, Jakarta.

Vogel, 1985, Buku Analisis Anorganik Kualitatif Makro dan Semimikro (Edisi kelima),diterjemahkan oleh Setiono dan Pudjaatmaka, PT.Kalma Media Pustaka, Jakarta:199. 